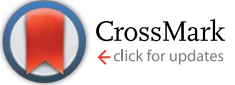

Cite this: RSC Adv., 2017, 7, 10469

Received 24th January 2017

Accepted 1st February 2017

DOI: $10.1039 / \mathrm{c} 7 \mathrm{ra01087g}$

rsc.li/rsc-advances

\section{Continuous flow synthesis of indoles by Pd-catalyzed deoxygenation of 2-nitrostilbenes with carbon monoxide $\uparrow$}

\author{
Gabriel Glotz, ${ }^{a}$ Bernhard Gutmann, ${ }^{\text {*ab }}$ Paul Hanselmann, ${ }^{c}$ Anna Kulesza, ${ }^{c}$ \\ Dominique Roberge ${ }^{\star c}$ and C. Oliver Kappe ${ }^{\star a b}$
}

\begin{abstract}
The palladium-catalyzed deoxygenation of $o$-vinylnitrobenzenes employing carbon monoxide as a terminal reductant produces indoles in a continuous flow environment. The reaction proceeds with catalyst loadings of 1 to $2 \mathrm{~mol} \% \mathrm{Pd}(\mathrm{OAc})_{2}$ in the presence of suitable ligands/additives and generates carbon dioxide as the only stoichiometric side-product. The reductive cyclization proceeds in a clean fashion with high initial reaction rates in the pressurized flow reactor, ultimately leading to deposition of catalytically inactive palladium(0) inside the channels of the flow device, allowing for an efficient catalyst recovery. A variety of o-vinylnitrobenzenes (o-nitrostilbenes and -styrenes) were converted to the corresponding indoles within 15 to $30 \mathrm{~min}$ at a reaction temperature of $140{ }^{\circ} \mathrm{C}$ to furnish products in good to excellent yields (10-20 bar CO pressure). Mechanistic aspects and the scope of the transformation are discussed.
\end{abstract}

\section{Introduction}

Indoles are among the most abundant heterocycles in nature and a vastly diverse array of natural and synthetic compounds contain the indole scaffold. Even though first methods for the generation of indoles were discovered well over a century ago, the ubiquity and structural diversity of biologically active indoles has continued to drive research towards their synthesis and functionalization. ${ }^{1}$ In particular, the development of regioselective methods for the construction of indoles with complex substitution patterns has remained an active area of research. ${ }^{1}$ In the 1960 s, Cadogan and Sundberg reported the generation of indoles by reductive cyclization of $o$-nitrostyrenes (cf. Scheme 1). ${ }^{2}$ For the Cadogan-Sundberg indole synthesis, the

$$
\text { Pd(OAc) }
$$

Scheme 1 Reductive cyclization of o-vinylnitrobenzenes.

\footnotetext{
Institute of Chemistry, University of Graz, NAWI Graz, Heinrichstrasse 28, 8010 Graz, Austria. E-mail: oliver.kappe@uni-graz.at

${ }^{b}$ Research Center Pharmaceutical Engineering (RCPE), Inffeldgasse 13, $8010 \mathrm{Graz}$, Austria

${ }^{c}$ Microreactor Technology, Lonza AG, CH-3930 Visp, Switzerland

$\dagger$ Electronic supplementary information (ESI) available: Further experimental results and optimization data; Wittig synthesis of $o$-nitrostilbenes and characterization data; ICPMS analysis of the processed reaction mixture; ${ }^{1} \mathrm{H}-\mathrm{NMR}$ and ${ }^{13} \mathrm{C}-\mathrm{NMR}$ spectra. See DOI: $10.1039 / \mathrm{c} 7 \mathrm{ra01087g}$
}

nitroaromatic compound is thereby typically heated in boiling triethyl phosphite to accomplish a deoxygenative cyclization. ${ }^{2}$ This approach is appealing for the construction of highly functionalized indoles, since the reaction is inherently regioselective and the respective starting materials can be assembled in a convergent manner by highly developed, robust transformations. On the other hand, the extreme reaction conditions (reaction temperatures in excess of $150{ }^{\circ} \mathrm{C}$ ) and the generation of large amounts of phosphorus waste renders this transformation increasingly unacceptable in contemporary organic synthesis. Transition metal catalyzed alternatives employing carbon monoxide as stoichiometric reducing agent were developed in the 1990s (Scheme 1). ${ }^{3}$ In particular, palladium-based systems have proven to be effective for this transformation. Watanabe and co-workers demonstrated a procedure for the reductive cyclization of 2-ethenyl-1-nitrobenzenes employing $\mathrm{PdCl}_{2}(\mathrm{PhCN})_{2}$ as catalyst and triphenylphosphine as the ligand. ${ }^{4}$ A stoichiometric amount of tin dichloride and a $\mathrm{CO}$ pressure of 20 bar was required to yield the corresponding indoles within a reaction time of $16 \mathrm{~h}$ at $100{ }^{\circ} \mathrm{C} .{ }^{4}$ Söderberg and co-workers accomplished the indolization with $6 \mathrm{~mol} \%$ $\mathrm{Pd}(\mathrm{OAc})_{2}$ and $24 \mathrm{~mol} \%$ triphenylphospine as ligand using MeCN as solvent. ${ }^{5}$ Typically, the reaction was completed after reaction times of $15 \mathrm{~h}$ at $70{ }^{\circ} \mathrm{C}$ under a CO pressure of 4 bar to furnish the indoles in fair to excellent yields (40 to $100 \%) .{ }^{5}$ More recent work has demonstrated the great potential of this transformation for the construction of functionalized indoles. ${ }^{6-8}$ For instance, a thorough study by Davies and coworkers revealed that the reaction proceeds under comparatively mild conditions and with high functional group tolerance. ${ }^{8}$ With catalyst loadings as low as $1 \mathrm{~mol} \%$, a variety of $o$ - 
nitrostyrenes were converted to the respective indoles within reaction times of $16 \mathrm{~h}$ at $80{ }^{\circ} \mathrm{C} .^{8}$ Alternative procedures using molybdenum hexacarbonyl $\left[\mathrm{Mo}(\mathrm{CO})_{6}\right]$ as a convenient but expensive source of $\mathrm{CO}$ have been developed. ${ }^{9}$

Even though the reductive cyclization of $o$-nitrostyrene derivatives with $\mathrm{CO}$ as stoichiometric reductant provides an appealing approach for the synthesis of indoles, the necessity to employ a highly toxic gas under elevated pressure and temperature has severely limited the practicality of this transformation. Continuous flow microreactors represent an excellent platform for multiphase reactions. ${ }^{\mathbf{1 0 - 1 2}}$ Since mass transfer between the phases is directly proportional to the interfacial area per unit volume, increasing interfacial area is crucial for achieving high reaction rates and to minimize unwanted side reactions in the homogeneous phase. Using dedicated continuous flow micromixers, specific interfacial areas orders of magnitude larger than in conventional stirred tank reactors can be established. ${ }^{\mathbf{1 0}-\mathbf{1 2}}$ Importantly, large, welldefined specific interfacial areas can be maintained up to high production volumes. In particular, gas-liquid reactions benefit tremendously from the unique characteristics of microreactors. ${ }^{\mathbf{1 2 , 1 3}}$ Gases can be dosed into the flow system with precise stoichiometry using mass flow controllers and intense mixing of the gaseous and liquid phase can be achieved. Furthermore, high pressure operation increases the concentration of the gas in the liquid phase (Henry's law). It is not surprising, therefore, that continuous flow reactions with gaseous carbon monoxide as reagent have found quite considerable usage. ${ }^{\mathbf{1 3 , 1 4}}$ Indeed, in several cases it was reported that carbonylation reactions in microreactors performed considerably cleaner compared to batch reactions under otherwise identical conditions. ${ }^{13}$

Herein we present an intensified continuous flow protocol for the reductive cyclization of $o$-vinylnitrobenzenes of type $\mathbf{1}$ (Scheme 1). The reactions proceeded with low catalyst loadings within residence times of only 15 to 30 minutes at $140{ }^{\circ} \mathrm{C}$ and CO pressures of 10-20 bar. The protocol was successfully applied for the generation of various 2-aryl-substituted indoles. The products were isolated with excellent purities, generally without the need for chromatography.

\section{Results \& discussion}

The initial flow reactor setup consisted of an HPLC pump for introducing the liquid feed (Scheme 2; see also Fig. S1 in the ESI $\dagger$ ). CO gas was fed from a gas cylinder into the system via a mass flow controller. The liquid and gaseous streams were combined in a simple stainless steel T-mixer at room temperature. The T-mixer was connected to the residence tube reactor via a fluoropolymer tubing (PFA, 1/16" o.d., $0.8 \mathrm{~mm}$ i.d.). The PFA tubing allowed visual observation of the flow profile. The residence time reactor was a $20 \mathrm{~mL}$ stainless steel coil heated on an aluminum heating block (Uniqsis FlowSyn). The processed reaction mixture finally exited the system through a short cooling loop in a water bath (1 mL stainless steel, $1 / 16^{\prime \prime}$ o.d., $1 \mathrm{~mm}$ i.d.) and an adjustable back-pressure regulator (0 to 25 bar). Pressure sensors were integrated into the T-mixer and

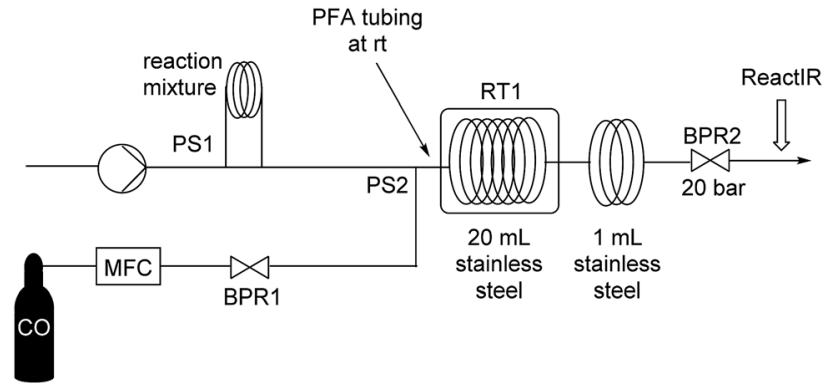

Scheme 2 Experimental setup for continuous flow deoxygenations with carbon monoxide.
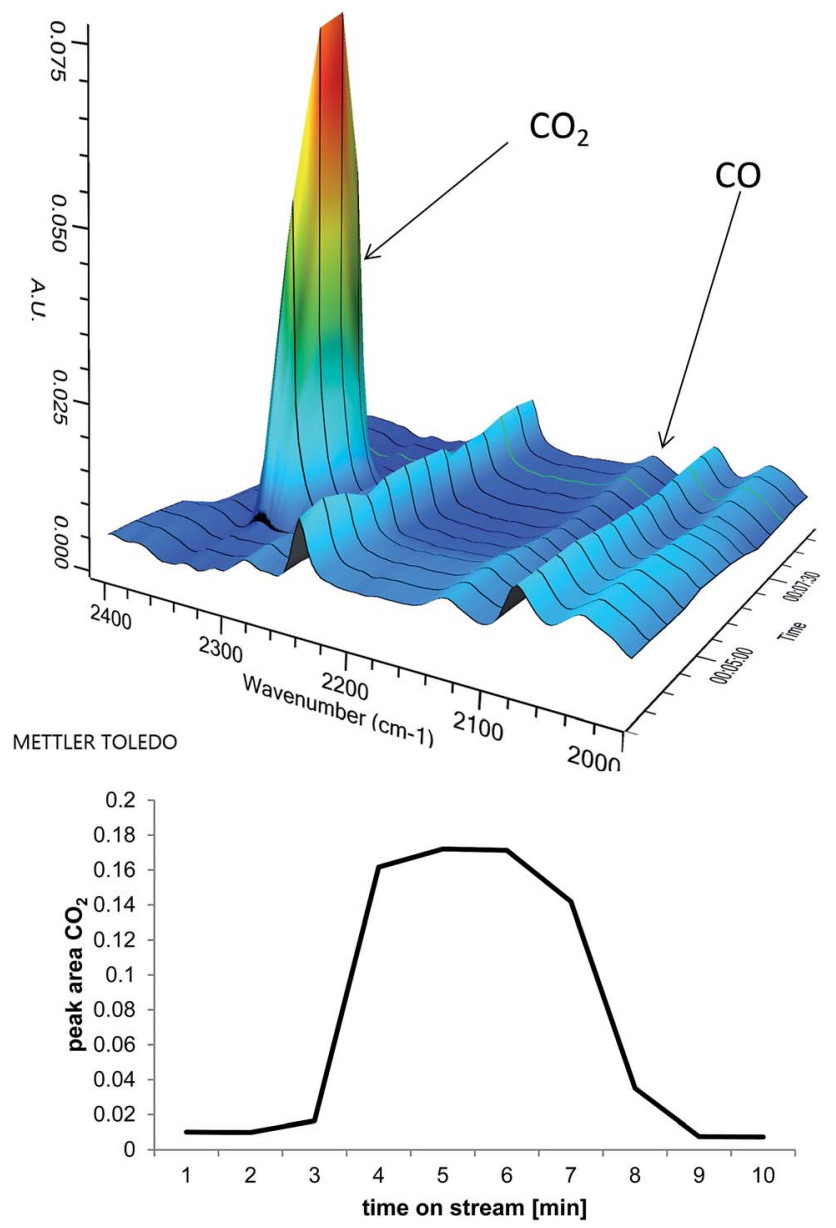

Fig. 1 Top: 3-D surface image showing for the strongly IR active asymmetrical stretch band of $\mathrm{CO}_{2}$ in the region from 2300 to 2400 $\mathrm{cm}^{-1}$, and the weaker $\mathrm{CO}$ absorption in the region of 2100 to 2200 $\mathrm{cm}^{-1}$. Bottom: evolution of $\mathrm{CO}_{2}$ during a reaction.

directly after the pump (PS1 and PS2; Scheme 2). The evolution of carbon dioxide during the reaction could be conveniently monitored by in-line FTIR analysis (Mettler Toledo ReactIR with silicon probe). ${ }^{15}$ The strongly IR active asymmetrical stretch band of $\mathrm{CO}_{2}$ in the region from 2300 to $2400 \mathrm{~cm}^{-1}$ was the dominant feature in the IR-spectrum (see Fig. 1). The weaker stretch band of CO was detectable in the region of 2100 and $2200 \mathrm{~cm}^{-1} \cdot{ }^{15}$ 
Table 1 Reductive cyclization of methyl 2-nitrocinnamate (1a) in various solvents at $120^{\circ} \mathrm{C}(\text { Scheme } 2)^{a}$

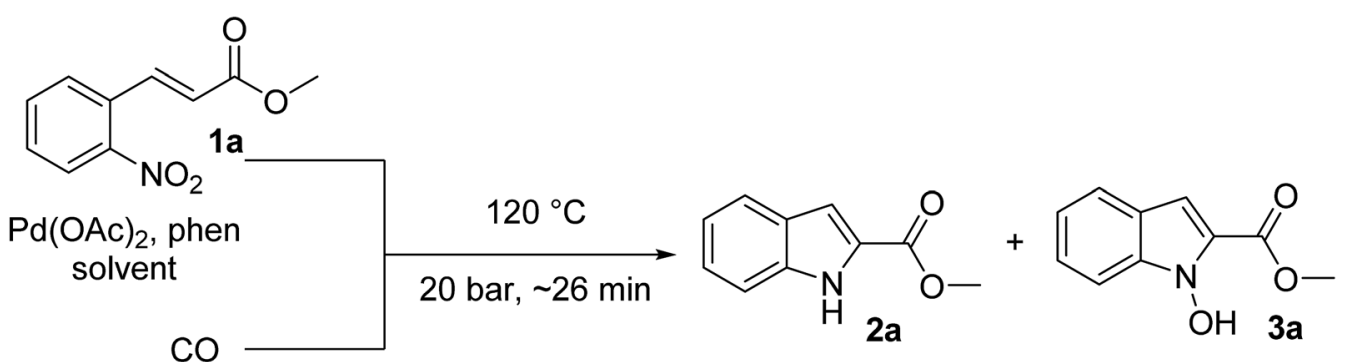

\begin{tabular}{|c|c|c|c|c|c|}
\hline 1 & $\mathrm{MeCN}$ & 14 & 85 & 1 & 1 \\
\hline 2 & DMF & 9 & 83 & 7 & 0 \\
\hline 4 & EtOAc & 20 & 45 & 35 & 0 \\
\hline 5 & Toluene & 1a not $\mathrm{s}$ & & & \\
\hline 6 & i-PrOH & 1a not $\mathrm{s}$ & & & \\
\hline
\end{tabular}

${ }^{a}$ Conditions: $0.9 \mathrm{mmol}$ substrate $1 \mathrm{a}, 2 \mathrm{~mol} \% \mathrm{Pd}(\mathrm{OAc})_{2}$ and $4 \mathrm{~mol} \%$ 1,10-phenanthroline in $3 \mathrm{~mL}$ solvent. Flow rate gas/liquid: $5.0 / 0.5 \mathrm{~mL}$ min ${ }^{-1}$ ( 1.4 equiv. of CO); $\sim 20$ bar pressure; residence time $\sim 30$ min (Scheme 2). ${ }^{b}$ HPLC peak area integration at 215 nm. ${ }^{c}$ Unidentified compounds.

Initial experiments were performed with methyl 2-nitrocinnamate (1a) as model substrate under conditions close to those reported by Davies and co-workers (Table 1$).^{8}$ For these reactions, $0.9 \mathrm{mmol}$ of the substrate, $\mathrm{Pd}(\mathrm{OAc})_{2}(2 \mathrm{~mol} \%)$ and 1,10-phenanthroline ligand (phen) were dissolved in the respective solvent $(3 \mathrm{~mL})$. The solutions were loaded into the sample loop of the 6port injection valve. When the reaction was started, the injection valve was switched and the reaction mixture was carried into the mixer, where it was combined with carbon monoxide. The liquid and the gaseous feed were pumped at flow rates of respectively 0.5 and $5 \mathrm{~mL} \mathrm{~min}^{-1}$ for the initial reactions. This corresponded to 1.4 equiv. of $\mathrm{CO}$ and thus less than required by stoichiometry (2 equiv.). The palladium(II) acetate was reduced to palladium(0) immediately upon contact with $\mathrm{CO}$ and the $\operatorname{Pd}(0)$ partly deposited on the PFA tubing which connected the T-mixer and the stainless steel residence coil (Scheme 2) ${ }^{16}$ Furthermore, palladium(0) particles were observed in the collected reaction mixtures. Even though considerable amounts of palladium were lost from the mixture by precipitation on the tubing, reasonable conversions and remarkably clean reactions were obtained (Table 1). The only side product detectable in the reaction mixture in appreciable amounts showed an $\mathrm{m} / \mathrm{z}$ of 191 , and is probably $N$-hydroxyindole

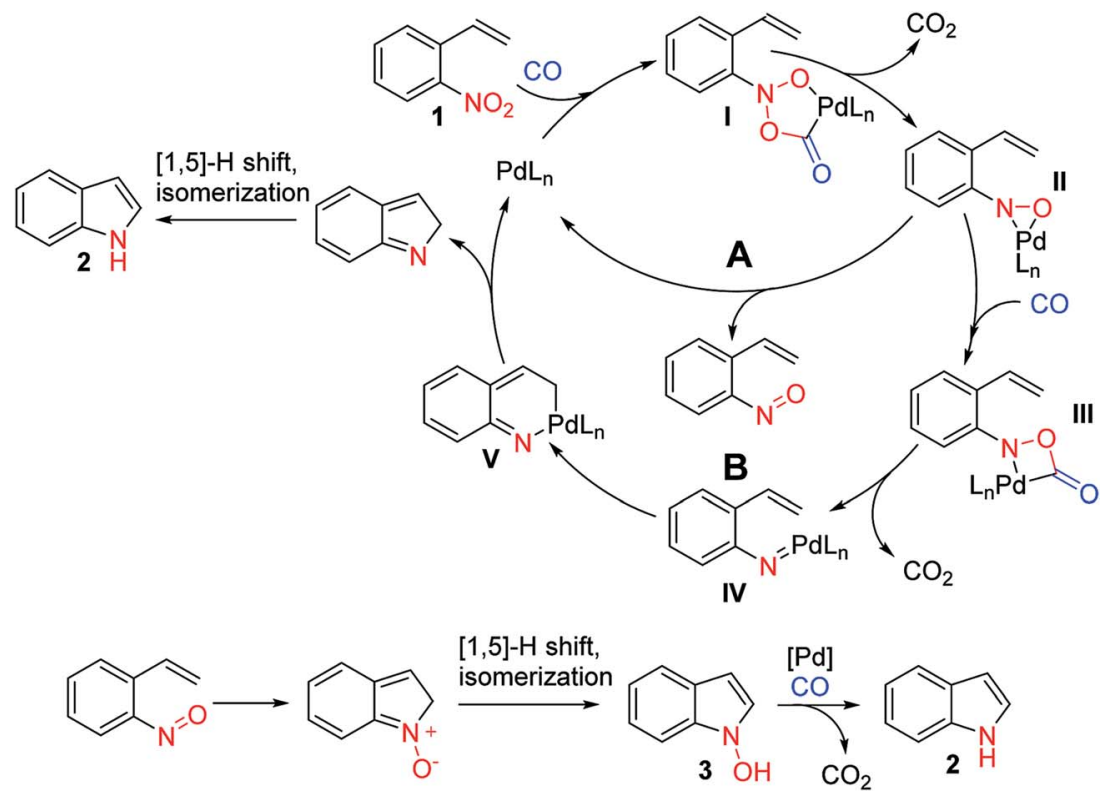

Scheme 3 Putative mechanisms for palladium-catalyzed indolization of 0 -nitrostyrene (coordination of Pd to the double bond of the 0 nitrostyrene has been omitted for clarity). ${ }^{7 b}$ 
3a (Table 1). Conversions of methyl 2-nitrocinnamate (1a) between 80 and $90 \%$ were obtained in all tested solvents after a residence time of $\sim 30 \mathrm{~min}$ at $120^{\circ} \mathrm{C}$ (Table 1 ). DMF and MeCN stabilize the palladium(0) better than the other tested solvents and less Pdparticles were found in the processed reaction mixtures. Only traces of $N$-hydroxyindole $3 \mathbf{a}$ were formed in $\mathrm{MeCN}$ as solvent. In contrast, significant amounts of $N$-hydroxyindole 3a were produced in less polar solvents, such as dioxane and EtOAc. Interestingly, the corresponding reaction with 2-nitrocinnamic acid did not provide the expected indole-2-carboxylic acid as product. Instead, compounds derived from nitro reduction and from decarboxylation with subsequent reductive cyclization were formed (Scheme S1 in the ESI $\dagger$ ).

Formation of $\mathrm{N}$-hydroxyindoles has previously been reported for reductive cyclizations involving $\mathrm{CO}$ and has been taken as evidence for a reaction mechanism involving partial deoxygenation of nitrostyrene to a nitrosostyrene intermediate (mechanism A in Scheme 3). ${ }^{8}$ Spontaneous intramolecular electrocyclization of the nitrosostyrene, followed by $[1,5]$ hydrogen shift and isomerization yields the $N$-hydroxyindole $3 .^{17}$ A subsequent palladium-catalyzed reduction of the $N$-hydroxyindole $\mathbf{3}$ with $\mathrm{CO}$ as terminal reductant forms indole 2 as the final product (Scheme 3). ${ }^{8}$ In contrast, earlier mechanistic investigations by Watanabe, Cenini, and Söderberg have suggested the formation of a metal nitrene as intermediate (IV) by exhaustive deoxygenation of the nitrostyrene $\mathbf{1}$ (mechanism $\mathrm{B}$ in Scheme 3)..$^{3,4}$ Cyclization followed by reductive elimination directly generates the indole 2 without a $N$-hydroxyindole intermediate. ${ }^{7}$ As suggested by Söderberg, both mechanisms may operate depending on the specific reaction conditions. ${ }^{\boldsymbol{b}}{ }^{\boldsymbol{b}}$ This is supported by kinetic data from our laboratory, acquired in various solvents and at various temperatures. The latter cycle (B) predominates in MeCN as solvent, while hydroxyindole 3a slowly accumulates in EtOAc or toluene (for additional experiments, see the ESI $\dagger$ ).

For subsequent experiments the catalyst loading was further reduced to $1 \mathrm{~mol} \%$. At this catalyst loading, the conversion increased significantly with increasing 1,10-phenanthroline loading. Probably, the phenanthroline ligand stabilizes the $\operatorname{Pd}(0)$ and prevents deposition of Pd black on the tubing wall (Table 2).

As expected, better conversions were obtained with increased stoichiometry of CO. However, more than 2 equiv. of CO did not increase the conversion further (Table $\mathrm{S} 2$ in the ESI $\dagger$ ). In

Table 2 Influence of 1,10-phenanthroline ligand loading ${ }^{a}$

\begin{tabular}{lllll}
\hline & phen $(\%)$ & $\mathbf{1 a}^{b}(\%)$ & $\mathbf{2 a}^{b}(\%)$ & Others $^{b, c}(\%)$ \\
\hline 1 & $1 \%$ & 82 & 18 & 0 \\
2 & $2 \%$ & 54 & 42 & 4 \\
3 & $4 \%$ & 32 & 65 & 3 \\
4 & $8 \%$ & 27 & 67 & 4
\end{tabular}

${ }^{a}$ Conditions: 0.9 mmol substrate 1a, 1 mol\% $\operatorname{Pd}(\mathrm{OAc})_{2}, \quad 1,10-$ phenanthroline in $3 \mathrm{~mL}$ MeCN. Flow rate gas/liquid: $5.0 / 0.5 \mathrm{~mL}$ $\min ^{-1}\left(\sim 1.4\right.$ equiv. CO); $\sim 20$ bar pressure; $120{ }^{\circ} \mathrm{C}$; residence time $\sim 30$ min (Scheme 2). ${ }^{b}$ HPLC peak area integration at $215 \mathrm{~nm}$. ${ }^{c}$ Unidentified compounds. addition, temperature and reaction time had surprisingly little effect on the reaction (see Table 3). In particular, decreasing the residence time did not decrease the conversion as strongly as expected. Indeed, at a reaction temperature of $140{ }^{\circ} \mathrm{C}$, the conversion increased with increasing flow rate (entries 1 to 4 in Table 3). We hypothesized that at higher flow rates less of the palladium precipitates on the initial PFA tubing at room temperature ( $c f$. Scheme 2) and more palladium is therefore available in the stainless steel tube at $140{ }^{\circ} \mathrm{C}$. Therefore, all subsequent reactions were performed with a heated static mixer, to allow the combination of the gaseous CO feed with the liquid reaction mixture directly at elevated temperatures (Uniqsis glass static mixer; $1.8 \mathrm{~mL}$ mixing volume). With the static mixer heated to $140{ }^{\circ} \mathrm{C}$, the conversion increased to $>90 \%$ (entry 6 in Table 3). The stainless steel residence coil was then removed, still providing $>90 \%$ conversion after a residence time of $\sim 3 \mathrm{~min}$ at $160{ }^{\circ} \mathrm{C}$ (entry 8 in Table 3 ). The reaction was remarkably clean with methyl indole-2-carboxylate (3b) as the virtually only product. Even with a catalyst loading of only 1 mol\%, palladium(0) immediately formed upon contact with CO and precipitated on the channels of the static mixer. Indeed, after only a few experiments, a palladium film covered the channel of the static mixer over most of its length (Fig. S4 in the ESI $\dagger$ ). Notably, the palladium(0) on the mixer showed no catalytic activity for reductive cyclization (entry 10 in Table 3). Decreasing the amount of $\mathrm{Pd}(\mathrm{OAc})_{2}$ below 1 mol\% decreased the conversions significantly (entry 9 in Table 3 ).

Davies and co-workers obtained efficient cyclization at low catalyst loading with 3,4,7,8-tetramethyl-1,10-phenanthroline (tm-phen) as ligand in DMF as solvent. ${ }^{8}$ Under our conditions, reactions with phenanthroline provided slightly better results than reactions with tm-phen (entry 1 and 2 in Table 4). Furthermore, despite the similar structure of phen and bipyridyl, the conversion decreased to $<5 \%$ using the latter ligand (entry 3 and 4 in Table 4). Likewise, essentially no reaction was observed using 4,5-diazafluoren-9-one (daf) as ligand (entry 5 in Table 4). The palladium-catalyzed reductive cyclization is often performed using phosphines as ligands. ${ }^{5,6}$ Surprisingly, methyl 2-nitrocinnamate (1a) exhibited only low reactivity in the presence of various phosphine ligands under the present reaction conditions (conversion $<10 \%$; entry 7 in Tables 4 and S3 in the ESI $\dagger$ ). Better results were obtained with mixtures of phenanthroline and phosphines (entry 8 to 11 in Table 4). Palladium(0) in combination with mixtures of phen and bidentate phosphine ligands was identified as an efficient catalyst system by Söderberg. ${ }^{7}$ However, in our hands, significant amounts of the $N$-hydroxyindole 3 a were formed using these conditions.

As shown in Table 4, best results were obtained with 1,10phenanthroline as ligand (entry 1 in Table 4). With $1 \mathrm{~mol} \%$ $\mathrm{Pd}(\mathrm{OAc})_{2}$ and $4 \mathrm{~mol} \%$ ligand, conversions of $\sim 70 \%$ were achieved after a residence time of $\sim 3 \mathrm{~min}$ at $140{ }^{\circ} \mathrm{C}$. Increasing the residence time above $\sim 3$ min did not increase the conversion appreciably (Fig. 2a). Furthermore, increasing the temperature did not drive the reaction to completion (Fig. 2b). Gratifyingly, the addition of tributylamine further stabilized palladium. The reaction proceeded to $>90 \%$ conversion within a residence time of $15 \mathrm{~min}$ at $140{ }^{\circ} \mathrm{C}$ even with reduced amounts of 
Table 3 Continuous flow reductive cyclization of $1 \mathrm{a}$ with and without a static mixer ${ }^{a}$

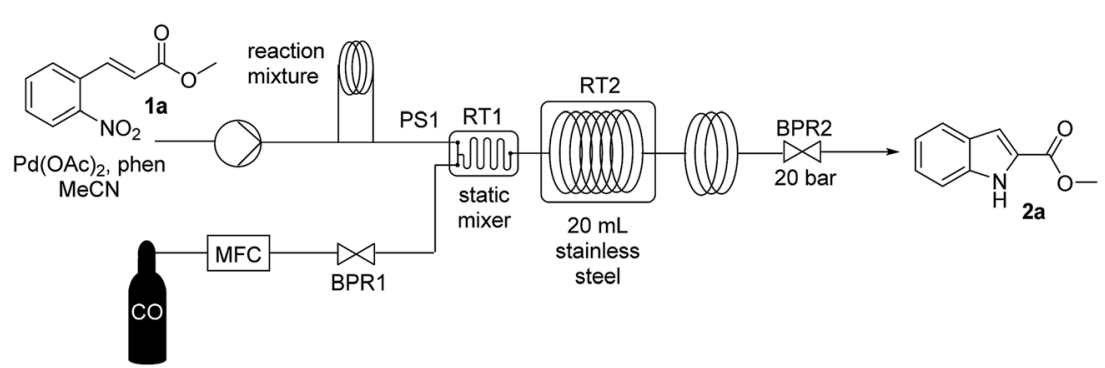

\begin{tabular}{|c|c|c|c|c|c|c|c|c|c|}
\hline & $\begin{array}{l}\mathrm{Pd}(\mathrm{OAc})_{2} / \text { phen } \\
(\mathrm{mol} \%)\end{array}$ & $\begin{array}{l}\text { Flow rate liquid } \\
\left(\mathrm{mL} \min ^{-1}\right)\end{array}$ & $\begin{array}{l}\text { Flow rate CO } \\
\left(\mathrm{mL} \min ^{-1}\right)\end{array}$ & $\begin{array}{l}\text { Temp RT1 }{ }^{b} \\
\left({ }^{\circ} \mathrm{C}\right)\end{array}$ & $\begin{array}{l}\text { Temp RT2 }{ }^{b} \\
\left({ }^{\circ} \mathrm{C}\right)\end{array}$ & $\begin{array}{l}\mathrm{rt}^{c} \\
(\mathrm{~min})\end{array}$ & $\begin{array}{l}1^{d} \\
(\%)\end{array}$ & $\begin{array}{l}2 \mathbf{a}^{d} \\
(\%)\end{array}$ & $\begin{array}{l}\text { Others }{ }^{d, e} \\
(\%)\end{array}$ \\
\hline 1 & $1 / 4$ & 0.5 & 8 & - & 140 & 22 & 39 & 61 & 0 \\
\hline 2 & $1 / 4$ & 1 & 16 & - & 140 & 11 & 28 & 72 & 0 \\
\hline 3 & $1 / 4$ & 2 & 32 & - & 140 & 5 & 24 & 76 & 0 \\
\hline 4 & $1 / 4$ & 3 & 48 & - & 140 & 3 & 21 & 79 & 0 \\
\hline 5 & $1 / 4$ & 0.5 & 8 & 110 & 140 & 20 & 19 & 80 & 1 \\
\hline 6 & $1 / 4$ & 0.5 & 8 & 140 & 140 & 23 & 7 & 92 & 1 \\
\hline 7 & $1 / 4$ & 0.5 & 8 & 140 & - & 3 & 34 & 65 & 1 \\
\hline 8 & $1 / 4$ & 0.5 & 8 & 160 & - & 3 & 7 & 92 & 1 \\
\hline 9 & $0.5 / 2$ & 0.5 & 8 & 160 & - & 3 & 56 & 44 & 0 \\
\hline 10 & $0 / 4$ & 0.5 & 8 & 160 & - & 3 & 100 & 0 & 0 \\
\hline
\end{tabular}

${ }^{a}$ Conditions: $0.9 \mathrm{mmol}$ substrate 1a, Pd(OAc) $)_{2}$ and 1,10-phenanthroline in $3 \mathrm{~mL} \mathrm{MeCN} ; \sim 2.2$ equiv. of CO; $\sim 20$ bar pressure. ${ }^{b}$ Temp RT1/RT2 $=$ temperature of static mixer/stainless steel residence tube. ${ }^{c} \mathrm{rt}=$ residence time (see Experimental section for details). ${ }^{d}$ HPLC peak area integration at $215 \mathrm{~nm} .{ }^{e}$ Unidentified compounds.

Table 4 Continuous flow reductive cyclization of $3 \mathrm{~b}$ in the presence of various nitrogen ligands ${ }^{a}$<smiles>Oc1ccnc2c1ccc1cccnc12</smiles><smiles>Cc1cnc2c(ccc3c(C)c([GaH2])ccc32)c1C</smiles><smiles>O=C1c2cccnc2-c2ncccc21</smiles><smiles>c1ccc(-c2ccccn2)nc1</smiles><smiles>Cc1ccnc(-c2cc(C)ccn2)c1</smiles><smiles>Pc1ccccc1</smiles>

dm-bipy

dppp

\begin{tabular}{|c|c|c|c|c|c|}
\hline 1 & phen (4) & 31 & 69 & 0 & 0 \\
\hline 2 & tm-phen (4) & 39 & 60 & 0 & 1 \\
\hline 4 & dm-bipy (4) & 96 & 4 & 0 & 0 \\
\hline 5 & $\operatorname{daf}(4)$ & 99 & 1 & 0 & 0 \\
\hline 7 & dppp (4) & 92 & 6 & 0 & 2 \\
\hline 10 & phen/dppp $(2: 2)$ & 15 & 56 & 26 & 3 \\
\hline 11 & phen/dppp $(1: 3)$ & 49 & 19 & 28 & 4 \\
\hline
\end{tabular}

${ }^{a}$ Conditions: $0.9 \mathrm{mmol}$ substrate 1a, $1 \mathrm{~mol} \% \mathrm{Pd}(\mathrm{OAc})_{2}$ and $4 \mathrm{~mol} \%$ ligand in $3 \mathrm{~mL} \mathrm{MeCN}$. Flow rate gas/liquid: $8 / 0.5 \mathrm{~mL} \mathrm{~min}^{-1}(\sim 2.2 \mathrm{equiv}$. CO); $\sim 20$ bar pressure; $140{ }^{\circ} \mathrm{C} ; \sim 3$ min residence time (RT1). ${ }^{b}$ HPLC peak area integration at $215 \mathrm{~nm} .{ }^{c}$ Unidentified compounds.

phenanthroline (Fig. 2). The reaction remained very clean and only the expected indole 2a was detected by HPLC-UV/Vis analysis. Upon concentration of the processed mixture to about $50 \%$ of its original volume, the pure indole $2 \mathrm{a}$ precipitated from the solution and was isolated by filtration in $81 \%$ yield. 

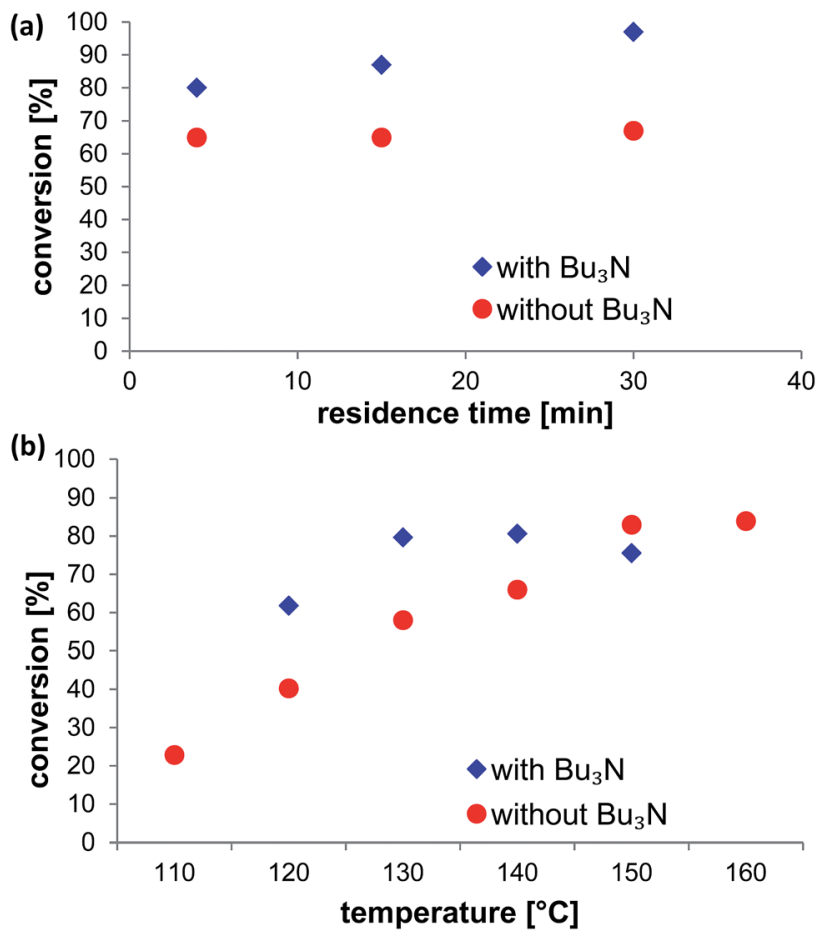

Fig. 2 HPLC conversions after reactions with various residence times $\left(140{ }^{\circ} \mathrm{C}\right.$; (a)) and temperature ( 3 min residence time; (b)) using $\mathrm{Pd}(\mathrm{OAc})_{2} /$ phen $(1 \mathrm{~mol} \% / 4 \mathrm{~mol} \%)$ or $\mathrm{Pd}(\mathrm{OAc})_{2} /$ phen $/ \mathrm{Bu}_{3} \mathrm{~N}(1 \mathrm{~mol} \% / 2$ $\mathrm{mol} \% / 20 \mathrm{~mol} \%)$ as catalyst system.

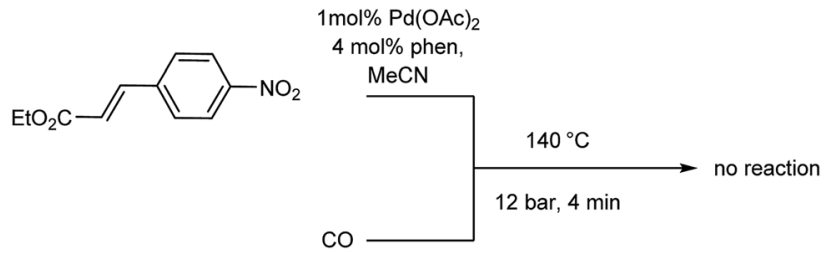

Scheme 4 Unsuccessful attempts for the reduction of nitro arenes.

Palladium phenanthroline complexes have been demonstrated to be among the most active catalysts for the reductive carbonylation of nitrobenzenes to isocyanates. ${ }^{18}$ However, nitroaromatic compounds did not react under the reaction conditions employed for the reductive cyclization (see Table S4 in the ESI $\dagger$ ). Neither nitrobenzenes with electron-withdrawing nor with electron-donating substituents exhibited any reactivity. Notably, ethyl 4-nitrocinnamate was recovered unchanged after subjecting it to the reaction conditions (Scheme 4). As already observed by Söderberg, a close proximity of the double bond to the nitro group seems to be crucial for the reduction to occur. ${ }^{5}$ Indeed, the presence of nitrobenzene apparently interferes with the reductive cyclization and nitrostilbene $\mathbf{1 b}$ did not cyclize in the presence of $9 \%$ nitrobenzene (see Table S5 in the ESI†). A similar observation was reported by Söderberg and co-workers. ${ }^{6 b}$

With optimized conditions for the reductive cyclization in hand, the scope was briefly investigated using a variety of substituted $o$-nitrostilbenes. The corresponding $o$-nitrostilbenes were easily prepared employing sealed vessel microwave heating using an aqueous/ $\mathrm{CHCl}_{3}$-biphasic Wittig reaction (40 min at $100{ }^{\circ} \mathrm{C}$, see the ESI $\dagger$ ). ${ }^{19}$ The nitrostilbenes were isolated as $E / Z$ mixtures after column chromatography in good to excellent yields. The $E / Z$ mixture of $\mathbf{1} \mathbf{j}$ was further separated by column chromatography to give pure $\boldsymbol{E}-\mathbf{1 j}$ and $Z-\mathbf{1 j}$ in 23 and $51 \%$ yield, respectively (see the ESI†). The reductive cyclization of stilbenes 1 was performed in the flow system shown in Table 3 using the glass static mixer and a subsequent $20 \mathrm{~mL}$ stainless steel tube reactor (Table 5). The amount of catalyst was increased to $2 \mathrm{~mol} \%$ for these reactions. No further optimization was attempted as it has previously been reported that the reaction is largely independent of the substitution pattern and the electronic properties of the substituents on the aromatic rings. ${ }^{5,6,7}$ In contrast to these previous reports, the conversion obtained for the continuous flow reactions using our experimental conditions depended strongly on the electron density of the stilbene. For instance, while reactions proceeded to high conversions with stilbenes bearing an electron withdrawing $\mathrm{CF}_{3}$-moity ( $1 \mathrm{~b}$ to $1 \mathrm{e}$ ), conversions $<16 \%$ were obtained for stilbenes $1 \mathbf{k}$ to $\mathbf{1 m}$ with the strongly electron donating $\mathrm{NMe}_{2}$ group on the aromatic ring containing the nitro group (Table 5). Reprocessing of the mixture did not increase the conversion appreciably. Furthermore, increasing reaction temperature did not have a noticeable effect. With the cyanoderivative, (Z)-4-(2-nitrostyryl)benzonitrile $Z \mathbf{Z}-\mathbf{1} \mathbf{j}$, the conversion increased to $57 \%$. After a second pass through the reactor, a conversion of $95 \%$ was obtained and the product was isolated in $74 \%$ yield (Table 5). A clear trend is not easily discernible from the experiments shown in Table 5, and both inherent reaction rate and stabilization of palladium $(0)$ by the stilbene are likely to play a decisive role. The intermediate homogeneous $\operatorname{Pd}(0)$ species have the tendency to aggregate to clusters, which ultimately irreversibly precipitate from the mixture in the form of catalytically inactive Pd black. Since $\pi$-complexation and stabilization of low-valent palladium by electron-poor alkenes is generally stronger, the active species is available for more catalytic cycles and the reaction proceeds to higher conversions in these cases. Reactions with substrates 1f to 1i proceeded to conversions ranging from $95 \%$ for the cyano substituted stilbene $\mathbf{1 f}$ to $14 \%$ for the fluoro derivative $\mathbf{1 i}$ (Table 5). Again, a second pass through the reactor did not drive the reaction to higher conversions. ICPMS analysis revealed that more than $90 \%$ of the palladium was already lost from the mixture after stilbene $\mathbf{1 f}$ and $\mathbf{1} \mathbf{g}$ were processed through the static mixer (no residence tube; $\sim 3$ min residence time; see Table $\mathrm{S6}$ in the ESI $†$ ). These results suggest that the palladium-catalyzed indolization is inherently fast, but the catalyst is quickly lost from the solution. In contrast, almost $50 \%$ of palladium was still present in the processed reaction mixture containing methyl 2nitrocinnamate (1a) as substrate. With no stabilizing alkene in the reaction mixture, $97 \%$ of the palladium was lost according to ICPMS analysis. Importantly, the palladium could be essentially quantitatively recovered from the static mixer by washing the reactor with aqua regia (Table S6 in the ESI†).

The stereochemistry of the alkene had little effect on the reaction and the indolization of both $\boldsymbol{E}-\mathbf{1} \mathbf{j}$ and $\mathbf{Z}-\mathbf{1} \mathbf{j}$ proceeded with essentially identical reaction rates (Table S7 in the ESI $\dagger$ ). Slightly 


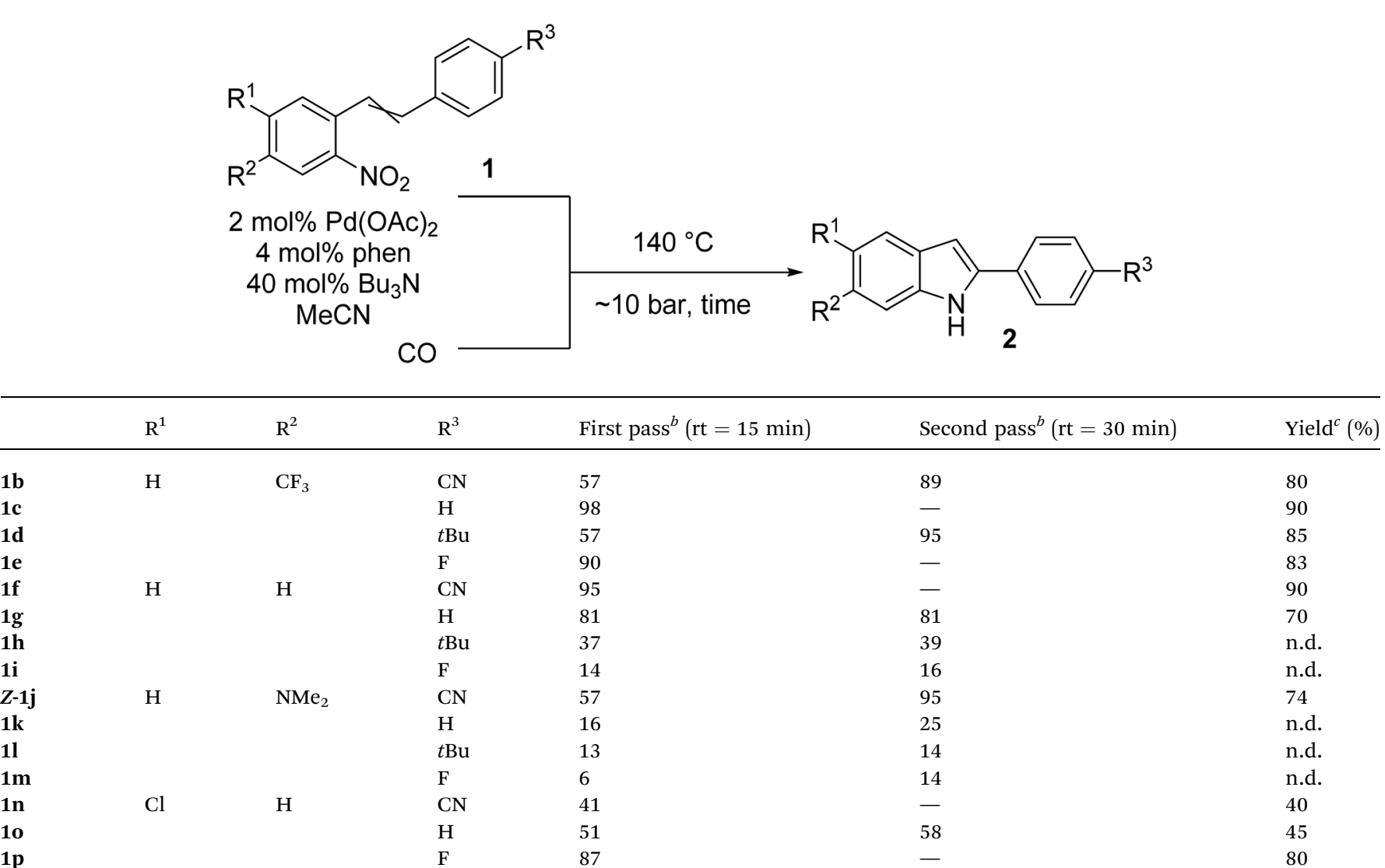

${ }^{a}$ Conditions: see Experimental section. ${ }^{b}$ HPLC peak area integration. ${ }^{c}$ Isolated yields of pure compounds. Purity of compounds was determined by ${ }^{1}$ H NMR, HPLC and GC-MS analysis. n.d. = not determined.

faster reactions were usually observed for the $E$ isomer when mixtures of the $E / Z$-stilbenes were processed (Table $S 7$ in the ESI $\dagger$ ). Even though full conversion was not obtained for all stilbenes under the present reaction conditions, the reactions were very clean and only the expected indole was observed by HPLC$\mathrm{UV} / \mathrm{Vis}$ analysis of the crude reaction mixtures. Indole 1n immediately crystallized from the mixture after the continuous flow reaction and was isolated by simple filtration. Indole $\mathbf{1 b}$ was isolated by column chromatography. For the other indoles, the solvent was evaporated and the products were finally recrystallized from petroleum ether (see Experimental section for details).

The reaction was finally scaled up to $60 \mathrm{~mL}(12 \mathrm{mmol}$ substrate) in the same reactor using methyl 2-nitrocinnamate (1a)

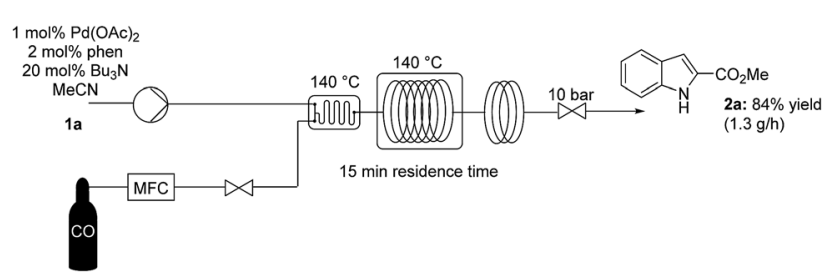

Scheme 5 Palladium-catalyzed reductive cyclization of methyl 2nitrocinnamate (1a). as substrate and $1 \mathrm{~mol} \%$ catalyst loading (Scheme 5). For this reaction the injection loop was removed and the HPLC pump was replaced by a high-pressure syringe pump. At a reaction time of $140{ }^{\circ} \mathrm{C}$ and a residence time of $15 \mathrm{~min}$, conversions of 95\% were afforded with 2-nitrocinnamate (1a) as substrate. The product crystalized from the mixture upon standing to furnish the pure indole $2 \mathrm{a}$ in $84 \%$ product yield. ICPMS analysis revealed that the isolated indole $2 \mathrm{a}$ contained $45 \mathrm{ppm}$ of palladium. Recrystallization of the indole reduced the amount to $16 \mathrm{ppm}$ without reducing product yield appreciably. ${ }^{20}$

\section{Conclusion}

We have presented a continuous flow reductive cyclization of various $o$-vinylnitrobenzenes with carbon monoxide as terminal reductant. The reaction was performed with catalyst loadings of 1 to $2 \mathrm{~mol} \% \mathrm{Pd}(\mathrm{OAc})_{2}$ using 1,10-phenanthroline/tributylamine as ligand system. The carbon monoxide reduced palladium(II) to palladium(0) nearly instantly and palladium quickly deposited on the channels of the flow system. Thus, for less reactive $o$ nitrostilbenes the reaction came to a halt before reasonable conversions were obtained. Nevertheless, in the pressurized flow reactor, reactions proceeded to high conversions for 
a variety of stilbenes within reaction times of 15 to $30 \mathrm{~min}$. In general, only the indole was detected in the crude reaction mixtures and the products were isolated in high purity without the need for column chromatography.

The reductive cyclization of $o$-nitrostyrenes provides a general and inherently regioselective approach to indoles. The reaction proceeds under neutral conditions and tolerates a broad range of functionality. The respective starting materials can be assembled in a convergent manner by well-developed, robust transformations. Furthermore, using $\mathrm{CO}$ as the stoichiometric reductant and palladium as catalyst, $\mathrm{CO}_{2}$ is the only stoichiometric by-product. The continuous flow indolization reported herein proceeded with reaction speeds 1 to 2 orders of magnitude faster than those reported for batch processes.

\section{Experimental section}

\section{General experimental conditions}

${ }^{1} \mathrm{H}$-NMR spectra were recorded on a Bruker $300 \mathrm{MHz}$ instrument. ${ }^{13} \mathrm{C}-\mathrm{NMR}$ spectra were recorded on the same instrument at $75 \mathrm{MHz}$. Chemical shifts $(\delta)$ are expressed in ppm downfield from TMS as internal standard. The letters s, d, t, q, and $\mathrm{m}$ are used to indicate singlet, doublet, triplet, quadruplet, and multiplet. High-resolution mass spectra were recorded on a FTICR-MS instrument using electrospray ionization (ESI) in positive mode. Low resolution mass spectra were obtained on a LCMS instrument using electrospray ionization (ESI) in positive or negative mode (Shimadzu LCMS-2020). GC-MS spectra were recorded using a Thermo Focus GC coupled with a Thermo DSQ II (EI, $70 \mathrm{eV})$. A HP5-MS column $(30 \mathrm{~m} \times 0.250 \mathrm{~mm} \times 0.025 \mu \mathrm{m})$ was used with helium as carrier gas $\left(1 \mathrm{~mL} \mathrm{~min}^{-1}\right.$ constant flow). The injector temperature was set to $280^{\circ} \mathrm{C}$. After $1 \mathrm{~min}$ at $50^{\circ} \mathrm{C}$ the temperature was increased in $25^{\circ} \mathrm{C} \min ^{-1}$ steps up to $300^{\circ} \mathrm{C}$ and kept at $300{ }^{\circ} \mathrm{C}$ for 4 minutes. Analytical HPLC (Shimadzu LC20) analysis was carried out on a C18 reversed-phase (RP) analytical column $(150 \times 4.6 \mathrm{~mm}$, particle size $5 \mu \mathrm{m})$ at $25{ }^{\circ} \mathrm{C}$ using a mobile phase A (water/acetonitrile $90: 10(\mathrm{v} / \mathrm{v})+0.1 \%$

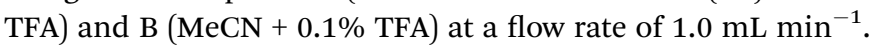
The following gradient was applied: linear increase from solution $30 \%$ B to $100 \%$ B in $8 \mathrm{~min}$, hold at $100 \%$ solution B for 2 min. Melting points were determined on a Stuart ${ }^{\mathrm{TM}}$ SMP3 melting point apparatus. Reagents and solvents were purchased from commercial sources and were used without further purification.

Caution: Carbon monoxide is a highly poisonous, colourless, odourless and tasteless gas. Reactions have to be performed in an efficient fume hood. Excess carbon monoxide should be directly vented into the exhaust duct of the fume hood. Carbon monoxide detectors must be used inside and outside the fume hood at all times!

\section{General procedure for indole synthesis (Table 5)}

The indole synthesis was performed in the flow setup shown in Table 3. The reactor consisted of an HPLC pump for introducing the liquid feed (Uniqsis FlowSyn). Carbon monoxide gas from a gas cylinder (N18, 98\% CO) was fed into the system via a calibrated mass flow controller (Bronkhorst). The liquid and gaseous streams were combined in a glass static mixer at $140{ }^{\circ} \mathrm{C}$ (GSM $2 \mathrm{~mL}$, Uniqsis). The mixer was connected to the residence tube reactor via a fluoropolymer tubing (PFA, 1/16" o.d., $0.8 \mathrm{~mm}$ i.d.). The residence coil reactor (stainless steel, $1 / 6^{\prime \prime}$ o.d., $1.0 \mathrm{~mm}$ i.d., $20 \mathrm{~mL}$ ) was heated on a heating block to $140{ }^{\circ} \mathrm{C}$ (Uniqsis FlowSyn). The reaction mixture exited the system through a short cooling loop and an adjustable back-pressure regulator (Swagelok KCB1H0A2A5P60000, 0-26 bar). The reaction mixtures consisted of $0.9 \mathrm{mmol}$ of stilbene, $2 \mathrm{~mol} \% \mathrm{Pd}(\mathrm{OAc})_{2}, 4$ mol\% of phenanthroline and $40 \mathrm{~mol} \%$ of tributylamine in $3 \mathrm{~mL}$ of MeCN (HPLC grade) as solvent. The mixtures were loaded into a $5 \mathrm{~mL}$ injection loop and injected from the loop into the reactor at flow rates of the liquid stream of $0.5 \mathrm{~mL} \mathrm{~min}^{-1}$ and a flow rate of the $\mathrm{CO}$ stream of $8.0 \mathrm{~mL} \mathrm{~min}^{-1}$. The total residence time was $15 \mathrm{~min}$ (determined by a stopwatch). Some starting materials were reprocessed under the same reaction conditions (see Table 5). Indole 1 n immediately crystallized from the mixture after the continuous flow reaction and was isolated by simple filtration. Indole $\mathbf{1 b}$ was isolated by column chromatography on silica gel using ethyl acetate and petroleum ether as eluent. For the other indoles, the solvent was evaporated. The remaining material dissolved in hot boiling petroleum ether and palladium was removed by filtration. After cooling to $-10{ }^{\circ} \mathrm{C}$, the obtained crystals were filtered off, washed with cold chloroform and dried in a drying oven at $50{ }^{\circ} \mathrm{C}$.

Methyl $\mathbf{1 H}$-indole-2-carboxylate (2a). Colorless crystals, mp 150-151 ${ }^{\circ} \mathrm{C}$ (lit. ${ }^{21} \mathrm{mp} \mathrm{151-152}{ }^{\circ} \mathrm{C}$ ), 81\% yield (127 mg, 0.73 mmol); ${ }^{1} \mathrm{H}$ NMR (300 MHz, DMSO-d 6 ) $\delta 11.94$ (brs, 1H), 7.66 (dd, $J=8.0,0.7 \mathrm{~Hz}, 1 \mathrm{H}), 7.46(\mathrm{dd}, J=8.3,0.9 \mathrm{~Hz}, 1 \mathrm{H}), 7.29-7.24(\mathrm{~m}$, 1H), 7.17-7.16 (m, 1H), 7.11-7.05 (m, 1H), $3.88(\mathrm{~s}, 3 \mathrm{H}) .{ }^{13} \mathrm{C}$ NMR (75 MHz, DMSO-d $\left.{ }_{6}\right) \delta 162.2,137.8,127.5,127.2,125.1,122.5$, 120.6, 113.0, 108.2, 52.3. MS (EI): $m / z: 175[\mathrm{M}]^{+}$.

4-(6-(Trifluoromethyl)-1H-indol-2-yl)benzonitrile (2b). White crystals, mp 201-202 ${ }^{\circ} \mathrm{C}$, 80\% yield (205 mg, $\left.0.71 \mathrm{mmol}\right) ;{ }^{1} \mathrm{H}$ NMR (300 MHz, acetone- $\left.\mathrm{d}_{6}\right) \delta 11.18$ (brs, 1H), 8.00-7.92 (m, 2H), 7.79-7.72 (m, 2H), 7.68 (d, $J=8.4 \mathrm{~Hz}, 1 \mathrm{H}), 7.65$ (d, $J=0.7 \mathrm{~Hz}$, $1 \mathrm{H}), 7.22$ (dd, $J=8.4,1.2 \mathrm{~Hz}, 1 \mathrm{H}), 7.13-7.07$ (m, 1H). ${ }^{13} \mathrm{C} \mathrm{NMR}$ (75 MHz, acetone- $\mathrm{d}_{6}$ ) $\delta 139.0,136.7,136.0,132.9,131.4,126.0$, $125.4(\mathrm{q}, J=270.6 \mathrm{~Hz}), 124.0(\mathrm{q}, J=31.8 \mathrm{~Hz}), 121.5,118.3,116.6$ $(\mathrm{q}, J=3.5 \mathrm{~Hz}), 111.1,108.9(\mathrm{q}, J=5.1 \mathrm{~Hz}), 101.7 ;{ }^{19} \mathrm{~F} \mathrm{NMR}(282$ MHz, acetone- $\left.\mathrm{d}_{6}\right) \delta-61.20(\mathrm{~s}), \mathrm{MS}(\mathrm{EI}): \mathrm{m} / z: 286[\mathrm{M}]^{+}$, HRMS (ESI): calc. for $\mathrm{C}_{16} \mathrm{H}_{10} \mathrm{~F}_{3} \mathrm{~N}_{2}{ }^{+} 285.0645[\mathrm{M}+\mathrm{H}]^{+}$, found 285.0643.

2-Phenyl-6-(trifluoromethyl)-1H-indole (2c). White crystals, $\mathrm{mp} 181-182{ }^{\circ} \mathrm{C}$ (lit. ${ }^{22} \mathrm{mp} 181-182{ }^{\circ} \mathrm{C}$ ), 90\% yield (211 mg, 0.81 $\mathrm{mmol}$ ); ${ }^{1} \mathrm{H}$ NMR (300 MHz, $\mathrm{CDCl}_{3}$ ) $\delta 8.56$ (brs, $\left.1 \mathrm{H}\right), 7.77-7.68$ $(\mathrm{m}, 4 \mathrm{H}), 7.54-7.47(\mathrm{~m}, 2 \mathrm{H}), 7.44-7.36(\mathrm{~m}, 2 \mathrm{H}), 6.90-6.89(\mathrm{~m}$, 1H). ${ }^{13} \mathrm{C} \mathrm{NMR}\left(75 \mathrm{MHz}, \mathrm{CDCl}_{3}\right) \delta 140.6,135.6,131.6,129.2$, 128.5, 125.4, $125.2(\mathrm{q}, J=271.5 \mathrm{~Hz}), 124.2(\mathrm{q}, J=31.9 \mathrm{~Hz}), 120.9$, 117.0 (q, $J=3.5 \mathrm{~Hz}), 108.4$ (q, $J=4.1 \mathrm{~Hz}), 100.0$. MS (EI): $m / z$ : $260[\mathrm{M}]^{+} .{ }^{19} \mathrm{~F}$ NMR $\left(282 \mathrm{MHz}, \mathrm{CDCl}_{3}\right) \delta-60.93$.

2-(4-(tert-Butyl)phenyl)-6-(trifluoromethyl)-1H-indole (2d). White crystals, $\mathrm{mp} 107-108{ }^{\circ} \mathrm{C}, 85 \%$ yield $(242 \mathrm{mg}, 0.76 \mathrm{mmol})$; ${ }^{1} \mathrm{H}$ NMR $\left(300 \mathrm{MHz}, \mathrm{CDCl}_{3}\right) \delta 8.68$ (brs, $\left.1 \mathrm{H}\right), 7.73-7.68(\mathrm{~m}, 2 \mathrm{H})$, $7.65(\mathrm{~d}, J=8.5 \mathrm{~Hz}, 2 \mathrm{H}), 7.52(\mathrm{~d}, J=8.5 \mathrm{~Hz}, 2 \mathrm{H}), 7.37$ (d, $J=$ $9.2 \mathrm{~Hz}, 1 \mathrm{H}), 6.86(\mathrm{~m}, 1 \mathrm{H}), 1.39$ (s, 9H). ${ }^{13} \mathrm{C} \mathrm{NMR}\left(75 \mathrm{MHz}, \mathrm{CDCl}_{3}\right.$ ) 
$\delta 151.7,140.7,135.5,131.7,128.8,126.1,125.2,125.2(\mathrm{q}, J=$ $271.4 \mathrm{~Hz}$ ), 123.9 (q, $J=31.8 \mathrm{~Hz}), 120.7,116.8,108.3,99.5,34.7$, 31.2. ${ }^{19} \mathrm{~F}$ NMR (282 MHz, $\mathrm{CDCl}_{3}$ ) $\delta-60.87$. MS (EI): $\mathrm{m} / z: 317$ $[\mathrm{M}]^{+}$, HRMS (ESI): calc. for $\mathrm{C}_{19} \mathrm{H}_{19} \mathrm{~F}_{3} \mathrm{~N}^{+} 316.1319[\mathrm{M}+\mathrm{H}]^{+}$, found 316.1316 .

2-(4-Fluorophenyl)-6-(trifluoromethyl)-1H-indole (2e). White crystals, mp 121-122 ${ }^{\circ} \mathrm{C}$, 83\% yield (208 mg, $\left.0.75 \mathrm{mmol}\right) ;{ }^{1} \mathrm{H}$ NMR (300 MHz, acetone- $\mathrm{d}_{6}$ ) $\delta 10.97$ (brs, $\left.1 \mathrm{H}\right), 7.83-7.76(\mathrm{~m}, 2 \mathrm{H})$, 7.63-7.59 (m, 2H), 7.21-7.09 (m, 3H), 6.85 (d, $J=1.3 \mathrm{~Hz}, 1 \mathrm{H})$. ${ }^{13} \mathrm{C} \mathrm{NMR}\left(75 \mathrm{MHz}, \mathrm{CDCl}_{3}\right) \delta 162.8(\mathrm{~d}, J=248.8 \mathrm{~Hz}), 140.0,135.6$, 131.5, 127.9 (d, $J=3.3 \mathrm{~Hz}), 127.2(\mathrm{~d}, J=8.2 \mathrm{~Hz}), 125.1$ (q, $J=$ $271.5 \mathrm{~Hz}), 124.2$ (q, $J=32.0 \mathrm{~Hz}), 120.9,117.1$ (q, $J=3.4 \mathrm{~Hz}$ ), $116.24(\mathrm{~d}, J=21.9 \mathrm{~Hz}), 108.4(\mathrm{q}, J=4.0 \mathrm{~Hz}), 100.0 .{ }^{19} \mathrm{~F} \mathrm{NMR}(282$ MHz, acetone- $\left.\mathrm{d}_{6}\right) \delta-60.94(3 \mathrm{H}),-114.91(1 \mathrm{H})$. MS (EI): $m / z: 279$ $[\mathrm{M}]^{+}$.

4-(1H-Indol-2-yl)benzonitrile (2f). White crystals, mp 190$192{ }^{\circ} \mathrm{C}$ (lit. ${ }^{23} \mathrm{mp} 190-191{ }^{\circ} \mathrm{C}$ ), 90\% yield (176 mg, $\left.0.81 \mathrm{mmol}\right) ;{ }^{1} \mathrm{H}$ NMR (300 MHz, DMSO-d $\left.{ }_{6}\right) \delta 11.76$ (brs, 1H), 8.07-8.05 (m, 2H), $7.93-7.90(\mathrm{~m}, 2 \mathrm{H}), 7.58(\mathrm{~d}, J=7.9 \mathrm{~Hz}, 1 \mathrm{H}), 7.44(\mathrm{dd}, J=8.1$, $0.8 \mathrm{~Hz}, 1 \mathrm{H}), 7.19-7.14$ (m, 2H), 7.06-7.01 (m, 1H). ${ }^{13} \mathrm{C}$ NMR (75 MHz, DMSO-d $\left.{ }_{6}\right) \delta 138.1,137.0,136.0,133.3,128.8,125.8,123.2$, 121.1, 120.3, 119.5, 112.1, 109.6, 102.0. MS (EI): $m / z: 218[\mathrm{M}]^{+}$.

2-Phenyl-1H-indole (2g). White crystals, mp 190-191 ${ }^{\circ} \mathrm{C}$ (lit. $^{22}$ mp 186-187 $\left.{ }^{\circ} \mathrm{C}\right), 70 \%$ yield $(121 \mathrm{mg}, 0.63 \mathrm{mmol}),{ }^{1} \mathrm{H}$ NMR $(300$ MHz, acetone- $\left.\mathrm{d}_{6}\right) \delta 10.5$ (brs, $\left.1 \mathrm{H}\right), 7.75-7.69(\mathrm{~m}, 2 \mathrm{H}), 7.43(\mathrm{~d}, J=$ $7.9 \mathrm{~Hz}, 1 \mathrm{H}), 7.34-7.25(\mathrm{~m}, 3 \mathrm{H}), 7.20-7.13(\mathrm{~m}, 1 \mathrm{H}), 7.00-6.93(\mathrm{~m}$, $1 \mathrm{H}), 6.88(\mathrm{td}, J=7.5,1.1 \mathrm{~Hz}, 1 \mathrm{H}), 6.77-6.75(\mathrm{~m}, 1 \mathrm{H}) .{ }^{13} \mathrm{C} \mathrm{NMR}$ (75 MHz, acetone- $\mathrm{d}_{6}$ ) $\delta 137.9,137.5,132.7,129.3,128.9,127.4$, 125.0, 121.8, 120.2, 119.6, 111.1, 99.1. MS (EI): $m / z: 193[\mathrm{M}]^{+}$.

4-(6-(Dimethylamino)-1 $\boldsymbol{H}$-indol-2-yl)benzonitrile (2j). Yellow needles, mp 220-221 ${ }^{\circ} \mathrm{C}, 74 \%$ yield (174 mg, $\left.0.67 \mathrm{mmol}\right) ;{ }^{1} \mathrm{H}$ NMR (300 MHz, acetone- $\mathrm{d}_{6}$ ) $\delta 10.29$ (brs, 1H), 7.82-7.77 (m, 2H), $7.64-7.59(\mathrm{~m}, 2 \mathrm{H}), 7.29$ (d, $J=8.7 \mathrm{~Hz}, 1 \mathrm{H}), 6.86-6.82(\mathrm{~m}, 1 \mathrm{H})$, 6.64-6.58 (m, 1H), 6.56-6.55 (m, 1H), 2.81 (s, 6H). ${ }^{13} \mathrm{C}$ NMR (75 MHz, acetone- $\left.\mathrm{d}_{6}\right) \delta 148.8,140.0,137.3,133.4,132.6,124.4$, 121.2, 121.2, 118.8, 109.9, 108.8, 102.1, 93.8, 40.6. MS (pos-ESI): $m / z: 260[\mathrm{M}+\mathrm{H}]^{+}$, HRMS (ESI): calc. for $\mathrm{C}_{17} \mathrm{H}_{16} \mathrm{~N}_{3}{ }^{+} 260.1193[\mathrm{M}+$ $\mathrm{H}]^{+}$, found 260.1191 .

4-(5-Chloro-1H-indol-2-yl)benzonitrile (2n). White crystals, $\mathrm{mp} 198-200{ }^{\circ} \mathrm{C}, 40 \%$ yield (90 mg, $\left.0.36 \mathrm{mmol}\right) ;{ }^{1} \mathrm{H}$ NMR $(300$ MHz, acetone- $\left.\mathrm{d}_{6}\right) \delta 10.93$ (brs, $\left.1 \mathrm{H}\right), 7.94-7.89(\mathrm{~m}, 2 \mathrm{H}), 7.75-7.70$ $(\mathrm{m}, 2 \mathrm{H}), 7.50(\mathrm{~d}, J=2.0 \mathrm{~Hz}, 1 \mathrm{H}), 7.32(\mathrm{~d}, J=8.7 \mathrm{~Hz}, 1 \mathrm{H}), 7.02$ (dd, $J=8.7,2.0 \mathrm{~Hz}, 1 \mathrm{H}), 6.97(\mathrm{~s}, 1 \mathrm{H}) .{ }^{13} \mathrm{C} \mathrm{NMR}(75 \mathrm{MHz}$, acetone$\left.\mathrm{d}_{6}\right) \delta 137.5,136.4,136.3,132.8,130.1,125.7,125.2,123.0,119.9$, 118.4, 112.9, 110.7, 101.3. MS (EI): $m / z: 252[\mathrm{M}]^{+}$.

5-Chloro-2-phenyl-1H-indole (2o). White crystals, mp 196$197{ }^{\circ} \mathrm{C}$ (lit. ${ }^{24} \mathrm{mp} 195-196{ }^{\circ} \mathrm{C}$ ), $45 \%$ yield (91 mg, $\left.0.40 \mathrm{mmol}\right) ;{ }^{1} \mathrm{H}$ NMR (300 MHz, acetone- $\mathrm{d}_{6}$ ) $\delta 10.73$ (brs, $\left.1 \mathrm{H}\right), 7.76-7.70(\mathrm{~m}, 2 \mathrm{H})$, $7.44(\mathrm{~d}, J=2.0 \mathrm{~Hz}, 1 \mathrm{H}), 7.37-7.18(\mathrm{~m}, 4 \mathrm{H}), 6.96(\mathrm{dd}, J=8.6$, $2.1 \mathrm{~Hz}, 1 \mathrm{H}), 6.76(\mathrm{~d}, J=2.2 \mathrm{~Hz}, 1 \mathrm{H}) .{ }^{13} \mathrm{C} \mathrm{NMR}(75 \mathrm{MHz}$, acetone$\left.\mathrm{d}_{6}\right) \delta 139.7,135.9,132.1,130.4,129.0,127.8,125.2,124.8,121.7$, 119.4, 112.5, 98.7. MS (EI): $m / z: 227[\mathrm{M}]^{+}$.

5-Chloro-2-(4-fluorophenyl)-1H-indole (2p). White crystals, mp 165-166 ${ }^{\circ} \mathrm{C}$ (lit. ${ }^{25} \mathrm{mp} 167-168{ }^{\circ} \mathrm{C}$ ), 80\% yield (176 mg, 0.72 mmol); ${ }^{1} \mathrm{H}$ NMR (300 MHz, acetone-d 6 ) $\delta 10.72$ (brs, $1 \mathrm{H}$ ), 7.80$7.73(\mathrm{~m}, 2 \mathrm{H}), 7.44(\mathrm{~d}, J=2.0 \mathrm{~Hz}, 1 \mathrm{H}), 7.28(\mathrm{~d}, J=8.6 \mathrm{~Hz}, 1 \mathrm{H})$, 7.16-7.07 (m, 2H), 6.96 (dd, $J=8.6,2.1 \mathrm{~Hz}, 1 \mathrm{H}), 6.73(\mathrm{~s}, 1 \mathrm{H}) .{ }^{13} \mathrm{C}$
NMR (75 MHz, acetone-d 6 ) $\delta 162.4(\mathrm{~d}, J=245.7 \mathrm{~Hz}), 138.8$, 135.9, 130.4, 128.7, 127.3 (d, $J=8.2 \mathrm{~Hz}$ ), 124.8, 121.8, 119.3, $115.8(\mathrm{~d}, J=21.9 \mathrm{~Hz}), 112.5(\mathrm{~d}, J=3.8 \mathrm{~Hz}), 98.7 .{ }^{19} \mathrm{~F}$ NMR $(282$ MHz, acetone- $\left.\mathrm{d}_{6}\right) \delta-115.57$. MS (EI): $m / z: 244[\mathrm{M}]^{+}$.

\section{Acknowledgements}

Funding from NAWI Graz and Research Center Pharmaceutical Engineering (RCPE) for the ReactIR system is gratefully acknowledged. We thank Prof. W. Goessler (Graz University) for performing ICPMS analysis.

\section{Notes and references}

1 For reviews on recent advances in the field of indole synthesis, see: (a) D. F. Taber and P. K. Tirunahari, Tetrahedron, 2011, 67, 7195-7210; (b) G. R. Humphrey and J. T. Kuethe, Chem. Rev., 2006, 106, 2875-2911.

2 (a) R. J. Sundberg and T. Yamazaki, J. Org. Chem., 1967, 32, 290-294; (b) R. J. Sundberg, J. Org. Chem., 1965, 30, 36043610; (c) J. I. G. Cadogan, Synthesis, 1969, 1, 11-17; (d) J. I. G. Cadogan, Organo-phosphorus Reagents Org. Synth., 1979, 269-294; (e) For a recent example in synthesis, see: A. S. Cotterill, C. J. Moody and J. R. A. Roffey, Tetrahedron, 1995, 51, 7223-7230.

3 For early reports, see: (a) C. Crotti, S. Cenini, B. Rindone, S. Tollari and F. Demartinc, J. Chem. Soc., Chem. Commun., 1986, 784-786; (b) C. Crotti, S. Cenini, R. Todeschini and S. Tollari, J. Chem. Soc., Faraday Trans., 1991, 87, 28112820; (c) M. Pizzotti, S. Cenini, P. Psaro and S. Costanzi, J. Mol. Catal., 1990, 63, 299-304; (d) C. Crotti, S. Cenini, F. Ragaini, F. Porta and S. Tollari, J. Mol. Catal., 1992, 72, 283-298.

4 (a) M. Akazome, T. Kondo and Y. Watanabe, Chem. Lett., 1992, 769-772; (b) M. Akazome, T. Kondo and Y. Watanabe, J. Org. Chem., 1994, 59, 3375-3380.

5 B. C. Söderberg and J. A. Shriver, J. Org. Chem., 1997, 62, 5838-5845.

6 For further examples using $\mathrm{Pd}(\mathrm{OAc})_{2} /$ ligand as catalyst, see: (a) B. C. Söderberg, A. C. Chisnell, S. N. O'Neil and J. A. Shriver, J. Org. Chem., 1999, 64, 9731-9734; (b) B. C. G. Söderberg, S. R. Banini, M. R. Turner, A. R. Minter and A. K. Arrington, Synthesis, 2008, 6, 903-912; (c) B. C. G. Söderberg, J. W. Hubbard, S. R. Rector and S. N. O'Neil, Tetrahedron, 2005, 61, 3637-3649; (d) B. C. Söderberg, S. R. Rector and S. N. O'Neil, Tetrahedron Lett., 1999, 40, 3657-3660; (e) T. L. Scott and B. C. G. Söderberg, Tetrahedron, 2003, 59, 6323-6332; $(f)$ N. H. Ansari, C. A. Dacko, N. G. Akhmedov and B. C. G. Söderberg, J. Org. Chem., 2016, 81, 9337-9349.

7 (a) T. L. Scott and B. C. G. Söderberg, Tetrahedron Lett., 2002, 43, 1621-1624; (b) R. W. Clawson Jr, R. E. Deavers, N. G. Akhmedov and B. C. G. Söderberg, Tetrahedron, 2006, 62, 10829-10834.

8 I. W. Davies, J. H. Smitrovich, R. Sidler, C. Qu, V. Gresham and C. Bazaral, Tetrahedron, 2005, 61, 6425-6437. 
9 (a) F. Zhou, D.-S. Wang and T. G. Driver, Adv. Synth. Catal., 2015, 357, 3463-3468; (b) N. Jana, F. Zhou and T. G. Driver, J. Am. Chem. Soc., 2015, 137, 6738-6741.

10 For extensive treatises on microreactor and continuous flow technology, see: (a) Flow Chemistry, ed. F. Darvas, V. Hessel and G. Dorman, De Gruyter, Berlin, 2014; (b) Microreactors in Preparative Chemistry, ed. W. Reschetilowski, Wiley-VCH, Weinheim, 2013; (c) Microreactors in Organic Synthesis and Catalysis, ed. T. Wirth, Wiley-VCH, Weinheim, 2nd edn, 2013; (d) V. Hessel, J. C. Schouten, A. Renken, Y. Wang, and J.-i. Yoshida, Handbook of Micro Reactors, Wiley-VCH, Weinheim, 2009; (e) Chemical Reactions and Processes under Flow Conditions, ed. S. V. Luis and E. Garcia-Verdugo, RSC Green Chemistry, 2010.

11 For recent reviews on continuous flow chemistry, see: $(a)$ C. Wiles and P. Watts, Green Chem., 2014, 16, 55-62; (b) S. V. Ley, D. E. Fitzpatrick, R. J. Ingham and R. M. Myers, Angew. Chem., Int. Ed., 2015, 54, 3449-3464; (c) B. Gutmann, D. Cantillo and C. O. Kappe, Angew. Chem., Int. Ed., 2015, 54, 6688-6728; (d) V. Hessel, D. Kralisch, N. Kockmann, T. Noël and Q. Wang, ChemSusChem, 2013, 6, 746-789; (e) J. C. Pastre, D. L. Browne and S. V. Ley, Chem. Soc. Rev., 2013, 42, 8849-8869; $(f)$ D. T. McQuade and P. H. Seeberger, J. Org. Chem., 2013, 78, 6384-6389; $(g)$ M. Movsisyan, E. I. P. Delbeke, J. K. E. T. Berton, C. Battilocchio, S. V. Ley and C. V. Stevens, Chem. Soc. Rev., 2016, 45, 4892-4928.

12 For recent reviews on continuous flow gas-liquid reactions, see: (a) C. J. Mallia and I. R. Baxendale, Org. Process Res. Dev., 2016, 20, 327-360; (b) H. P. Gemoets, Y. Su, M. Shang, V. Hessel, R. Luque and T. Noël, Chem. Soc. Rev., 2016, 45, 83-117; (c) B. Pieber and C. O. Kappe, Top. Organomet. Chem., 2016, 57, 97-136.

13 For recent examples of reactions with CO gas in tubular flow reactors or microreactors, see: (a) Md. T. Rahman, T. Fukuyama, N. Kamata, M. Sato and I. Ryu, Chem. Commun., 2006, 2236-2238; (b) E. R. Murphy, J. R. Martinelli, N. Zaborenko, S. L. Buchwald and K. F. Jensen, Angew. Chem., Int. Ed., 2007, 46, 1734-1737; (c) X. Gong, P. W. Miller, A. D. Gee, N. J. Long, A. J. Mello and R. Vilar, Chem.-Eur. J., 2012, 18, 2768-2772; (d) P. W. Miller, N. J. Long, A. J. de Mello, R. Vilar, J. Passchier and A. Gee, Chem. Commun., 2006, 546-548; (e) P. W. Miller, N. J. Long, A. J. de Mello, R. Vilar, H. Audrain, D. Bender, J. Passchier and A. Gee, Angew. Chem., Int. Ed., 2007, 46, 2875-2878; (f) P. W. Miller,
L. E. Jennings, A. J. deMello, A. D. Gee, N. J. Long and R. Vilar, Adv. Synth. Catal., 2009, 351, 3260-3268.

14 For examples of reactions with CO using "tube-in-tube" reactors as gas addition tools, see: (a) C. J. Mallia, G. C. Walter and I. R. Baxendale, Beilstein J. Org. Chem., 2016, 12, 1503-1511; (b) M. A. Mercadante and N. E. Leadbeater, Org. Biomol. Chem., 2011, 9, 6575-6578; (c) C. Brancour, T. Fukuyama, Y. Mukai, T. Skrydstrup and I. Ryu, Org. Lett., 2013, 15, 2794-2797; (d) T. Fukuyama, Y. Mukai and I. Ryu, Beilstein J. Org. Chem., 2011, 7, 12881293; (e) U. Gross, P. Koos, M. O'Brien, A. Polyzos and S. V. Ley, Eur. J. Org. Chem., 2014, 6418-6430.

15 Ley and co-workers previously used the CO band for the inline determination of CO concentration in a continuous flow system: P. Koos, U. Gross, A. Polyzos, M. O'Brien, I. Baxendale and S. V. Ley, Org. Biomol. Chem., 2011, 9, 6903-6908.

16 Reduction of $\mathrm{Pd}(\mathrm{OAc})_{2}$ with $\mathrm{CO}$ was previously used in Heck reactions to generate $\operatorname{Pd}(0):(a)$ F. A. Siqueira, J. G. Taylor and C. R. D. Correia, Tetrahedron Lett., 2010, 51, 2102-2105; (b) A. H. L. Machado, M. A. de Sousa, D. C. S. Patto, L. F. S. Azevedo, F. I. Bombonato and C. R. D. Correia, Tetrahedron Lett., 2009, 50, 1222-1225.

17 I. W. Davies, V. A. Guner and K. N. Houk, Org. Lett., 2004, 6, 743-746.

18 E. Ragaini, S. Cenini and F. Demartin, J. Organomet. Chem., 1999, 586, 190-195, and references therein.

19 E. Sinkovec and M. Krajnc, Org. Process Res. Dev., 2011, 15, 817-823, and references therein.

20 The limit for the total amount of platinoid-group metals is $5 \mathrm{mg} \mathrm{kg}^{-1}$ (for dosages of up to $10 \mathrm{~g}$ per day). Guideline on the specification limits for residues of metal catalysts from the European Agency for the Evaluation of Medicinal Products (EMEA), 2007 (http://www.emea.europa.eu).

21 L. Angelo, O. Rosaria, R. Giovanni, S. Giovanni and U. Nicola, Heterocycles, 1988, 27, 1365-1376.

22 W. Huifeng, L. Yaming, J. Linlin, Z. Rong, J. Kun, Z. Defeng and D. Chunying, Org. Biomol. Chem., 2011, 9, 4983-4986.

23 A. M. Gary, C. Belgin and E. K. Lauren, J. Org. Chem., 2009, 74, 973-980.

24 J. H. William, A. P. Vincent and U. Yasuyuki, J. Org. Chem., 1981, 46, 4511-4515.

25 F. Da Settimo, F. Simorini, S. Taliani, C. La Motta, A. M. Marini, S. Salerno, M. Bellandi, E. Novellino, G. Greco, B. Cosimelli, E. Da Pozzo, B. S. Costa, M. Nicola and M. M. Claudia, J. Med. Chem., 2008, 51, 5798-5806. 